\title{
PENERAPAN METODE FUZZY UNTUK SMART FARMING HAMSTER BERBASIS IOT
}

\author{
Budi Garinanto, Suryo Adi Wibowo, Deddy Rudhistiar \\ Program Studi Teknik Informatika S1, Fakultas Teknologi Industri \\ Institut Teknologi Nasional Malang, Jalan Raya Karanglo km 2 Malang, Indonesia \\ 1718049@itn.scholar.ac.id
}

\begin{abstract}
ABSTRAK
Tak sedikit orang yang memiliki hobi untuk memelihara binatang yang mungil dan imut tersebut untuk mengisi waktu luang maupun untuk kepuasan sendiri. Dalam memelihara hamster ada beberapa hal yang perlu diperhatikan, yaitu antara lain ketersediaan pakan untuk si hamster, ketersediaan air untuk si hamster, kondisi suhu dan kelembaban yang ada pada kandang hamster harus dijaga sesuai keadaan normal hamster. Untuk suhu normal hamster berapa pada 17 hingga 23 derajat celcius dan untuk kelembabannya 40\% hingga $70 \%$ yang terkadang hal - hal tersebut sering kali terlalaikan oleh sang pemiliki hamster tersebut. Oleh karena itu melalui penelitian ini penulis bermaksud membuat alat monitoring yang dapat membantu pemilik hewan peliharaan hamster yang memang hobi untuk memeliharanya maupun yang hanya sedang ingin memelihara dalam memantau kondisi kandang hamster agar dapat menjaga kondisi hamster tetap pada keadaan yang baik walaupun ketika sang pemiliki binatang peliharaan hamster melakukan aktivitasnya kembali. Setelah dilakukan pengujian pada perangkat keras maupun lunak pada program yang telah dibuat menunjukkan bahwa website dapat bekerja dengan baik pada browser berikut Chrome versi 91.0.4472.106, Microsoft Edge versi 91.0.864.54 dan Mozilla Firefox versi 89. Nilai - nilai dari sensor dapat ditampilkan kembali pada halaman website. Dengan pengujian hardware didapatkan bahwa dapat membaca sensor dapat membaca nilai jarak antar sensor dengan pakan dengan persetase akurat hingga $94.93 \%$, berdasarkan pengujian sensor $d h t$, sensor $d h t$ dapat bekerja dengan tingkat keakuratan rata - rata $96.84 \%$ dalam membaca nilai suhu dan $78.06 \%$ untuk nilai kelembaban. Adapun pengujian untuk sensor water level yang menunjukkan bahwa tingkat akurat sensor water level adalah $39.43 \%$
\end{abstract}

Kata Kunci: Internet of Things, Arduino Uno, Hamster, Website

\section{PENDAHULUAN}

Hamster adalah binatang sejenis hewan pengerat, selain memiliki tubuh yang mungil hamster juga terlihat begitu menggemaskan yang membuatnya sangat cocok dijadikan binatang peliharaan di rumah. Karena ukurannya yang mungil maka tidak diperlukannya area yang luas bila ingin memeliharanya yang membuatnya dapat diletakan diberbagai lokasi di rumah. (Merdeka,2 020) Dalam memelihara hamster ada beberapa hal yang perlu diperhatikan, yaitu antara lain ketersediaan pakan untuk si hamster, ketersediaan air untuk si hamster, kondisi suhu dan kelembaban yang ada pada kandang hamster harus dijaga sesuai keadaan normal hamster. Untuk suhu normal hamster berapa pada 17 hingga 23 derajat celcius dan untuk kelembabannya $40 \%$ hingga $70 \%$ yang terkadang hal - hal tersebut sering kali terlalaikan oleh sang pemiliki hamster tersebut. (Wikihow)

Seiring berjalannya waktu teknologi - teknologi pun semakin berkembang, termasuk teknologi dibidang informasi. Kini penyampaian dan pengolahan informasi dapat dilakukan tanpa bantuan manusia. Salah satu kemampuan penyampaian informasi tersebut adalah IoT (Internet of Things) yang berkemampuan untuk mentramisikan data melalui jaringan nirkabel (Sekawan Media, 2020).
Berdasarkan paparan tersebut diketahui bahwa hingga saat ini masih banyak penghobi peliharaan hamster yang melakukan pengecekan keadaan atau kondisi kandang ataupun keadaan pakan dan minum masih tersedia atau habis secara langsung diwaktu kesibukannya. Oleh karena itu, melalui penelitian ini penulis menggagas pengembangan Smart Farming Hamster berbasis Iot. Gagasan yang dibahas adalah Smart Farming Hamster berbasis IoT ini dapat memudahkan penghobi peliharaan binatang hamster untuk memantau kondisi kandang hamster mereka dari suhu, kelembaban, status pakan, status air minum serta keamanan kandang apakah kandang sudah terkunci apa belum. Sistem ini juga dibekali kipas, ionizer, dan heater yang dapat nyala ataupun mati sendiri sesuai keadaan kandang. Dengan adanya produk penelitian, diharapkan agar dapat memonitoring keadaan kandang hamster saat pemilik sedang diluar rumah.

\section{TINJAUAN PUSTAKA}

\subsection{Penelitian Terdahulu}

Ajeng Ayutantri, Dik, Jeseph Dedy Irawan, Suryo Adi Wibowo (2021) pada penelitian yang berjudul "Penerapan IoT (Internet of Things) dalam Pembuatan Tempat Sampah Pintar untuk Rumah Kos" yang pada penelitian tersebut berfungsi untuk 
mendeteksi isi dari tempat sampah yang dimana nantinya datanya akan ditampilkan pada website. Data yang diambil yaitu kapasitas tempat sampah dengan menggunakan sensor ultrasonik, kelembaban sampah dengan menggunakan sensor dht22 dan sensor MQ135 untuk mendeteksi kadar kandungan gas yang terdapat dalam tempat sampah tersebut.

Firmanda Mucthar, Suryo Adi Wibowo, Ariwibisono (2021) pada penelitian yang berjudul "Penerapan IoT (Internet of Things) Terhadap Rancang Bangun Sangkar Burung Pintar Untuk Burung Teriep". Pada penelitian tersebut alat yang digunakan berupa sensor ultrasonik, sensor water level, dan dht11 yang digunakan untuk mengambil data untuk Sangkar Burung Pintar yang kemudian data tersebut akan ditampilkan pada website yang dimana data pada website akan terupdate setiap 30 menit sekali.

Shaifany (2019) pada penelitian dengan judul "MOBILE IOT (INTERNET OF THINGS) UNTUK PEMANTAUAN KUALITAS AIR HABITAT IKAN HIAS PADA AKUARIUM MENGGUNAKAN METODE LOGIKA FUZZY". Tujuan penelitian ini adalah agar masyarakat yang gemar memelihara ikan hias dapat mengawasi dan mengontrol pemberian pakan untuk ikan hias mereka pada akuarium tanpa harus turun tangan secara langsung dalam perawatannya. Adapula persamaan yang tedapat dari penelitian ini yakni sama - sama menggunakan suatu sistem monitoring yang sama, terdapat pemberian pakat secara jarak jauh dan yang membuat pembeda dari sistem yang dibuat oleh Shaifany adalah sistem yang dibuat digunakan untuk ikan.

Bakhtiyar (2017) pada penelitian dengan judul “Aplikasi Sensor Ultrasonik Untuk Deteksi posisi Jarak Pada Ruang Menggunakan Arduino Uno “. Tujuan dari penelitian ini adalah pengembangan deteksi jarak objek menggunakan sensor ultrasonic agar didapatkan nilai tingkat akurat yang tinggi. Ada juga persamaan dari penelitian tersebut yaitu sama sama menerapkan sensor ultrasonik untuk mendeteksi jarak antar benda dan membuat beda dari sistem yang dibuat oleh Bakhtiyar adalah sistem yang dibuat hanya deteksi jarak.

Abel (2017) pada penelitian dengan judul "PENERAPAN ALGORITMA FUZZY LOGIC SUGENO PADA SISTEM PEMBERI MAKAN LOBSTER OTOMATIS DAN MONITORING KEKERUHAN AIR “. Tujuan penelitian ini adalah untuk meningkatkan hasil dari budidaya lobster. Ada pula persamaan dari penelitian tersebut yaitu sama sama untuk sistem monitoring yang dapat digunakan untuk melakukan pemberian pakan secara jarak jauh dan yang membuat beda antara sistem yang dibuat Abel adalah objek yang digunakan lobster.

\subsection{Metode Fuzzy}

Sundari Retno (2013) Logika fuzzy merupakan salah satu komponen pembentuk soft computing. Dasar dari logika fuzzy terdapat pada teori himpunan fuzzy. Pada teori himpunan tersebut maka fuzzy derajat keanggotaan memiliki peranan untuk menentukan keberadaan dari suatu elemen yang ada didalam suatu himpunan. Logika fuzzy merupakan konsep dasar dari sistem fuzzy yang kemudian dapat untuk digunakan dalam melakukan perhitungan terhadap suatu variabel input berdasarkan nilai kesamarannya.

1. Himpunan Fuzzy

Pada himpunan fuzzy terdapat istilah crisp untuk menunjukan himpunan tegas, nilai keanggotaan dari suatu item $\mathrm{x}$ didalam sebuah himpunan $\mathrm{A}$ yang biasa ditulis $\mu \mathrm{A}(\mathrm{X})$ yang memiliki dua kemungkinan, yaitu

a. 1 (satu) yang memiliki arti yaitu suatu item menjadi tergabung didalam anggota suatu himpunan

b. 0 (nol) yang yang memiliki arti yaitu suatu item tidak tergabung kedalam anggota dari suatu himpunan

2. Fungsi Keanggotaan

Suatu garis kurva yang digunakan untuk menunjukkan pemetaan dari titik - titik input data kedalam keanggotaannya yang memiliki rentang nilai antara 0 hingga 1 . Adapun cara yang bisa dilakukan untuk memperoleh nilai keanggotaan adalah dengan cara pendekatan fungsi.

3. Operator Dasar Zadeh untuk Operasi Himpunan Fuzzy

1) Operator $A N D$

Operator yang berhubungan dengan operasi interseksi pada suatu himpunan. Hasil yang diperoleh dari operasi ini dengan mengambil nilai keanggotaan terkecil antara elemen pada himpunan yang bersangkutan

2) Operator $O R$

Operator yang berhubungan dengan operasi gabungan dari berberapa himpunan atau union pada himpunan. Hasil yang diperoleh dari operasi ini mendapatkan niai keanggotaan terbesar antar elemen pada himpunan yang bersangkutan.

3) Operator NOT

Operator yang mengambil dari operasi komplemen pada suatu himpunan. Hasil operasi yang diperoleh dengan mengurangkan nilai keanggotaan elemen pada himpunan yang bersangkutan dari 1

Akbar, Ariya (2015) Tsukamoto merupakan salah satu jenis dari metode fuzzy. Metode Tsukamoto adalah perluasan dari penalaran monoton, yang dimana setiap konsekuen pada aturan yang berbentuk If-Else harus direpresentasikan dengan suatu himpunan fuzzy dengan fungsi keanggotaan yang monoton. Sebagaimana hasilnya, output yang disajikan ialah sebuah hasil inferensi dari tiap - tiap aturan diberikan secara tegas ( crips ) berdasarkan $\alpha$ - 
predikat ( fire strength ) Hasil akhirnya diperoleh dengan menggunakan rata - rata terbobot

\subsection{Internet of Things (IOT)}

(Sekawan Media, 2020) Internet of Things, sering disebut sebagai IOT adalah suatu konsep yang dimana sebuah objek mempunyai kemapuan untuk mengirimkan atau mentransmisikan data melalui jaringan tanpa menggunakan bantuan seperti perangkat komputer dan manusia. IOT sendiri telah mengalami banyak perkembangan dimulai dari tingkat konvergensi teknologi nikabel, microelectromechanical atau $M E M S$, internet dan $Q R$ atau Quick Responses Code.

\subsection{XАMPP}

Menurut Andy Nugroho (2019) XAMPP adalah sebuah paket perangkat lunak computer sistem penamaannya diambil dari kata $\mathrm{X}$ untuk cross platform, A untuk Apache, M untuk MySQL, $\mathrm{P}$ untuk PHP dan $\mathrm{P}$ untuk Perl. XAMPP sendiri dapat perperan sebagai hosting local atau localhost. Localhost sendiri adalah sebuah server jaringan yang hanya dapat diakses oleh jaringan lokal saja. XAMPP selain bisa digunakan sebagai localhost, $X A M P P$ juga memiliki fitur $M y S Q L$ yang dimana $M y S Q L$ berfungsi sebagai database. Database merupakan kumpulan data - data yang telah terorganisir, yang pada umumnya date tersebut telah disimpan dan diakses secara elektronik dari suatu sistem computer.

\subsection{Website}

Menurut Waryanto (Niagahoster) Website adalah sebuah kumpulan halaman pada suatu domain di internet yang dibuat dengan tujuan tertentu dan saling berhubungan serta dapat diakses secara luas menggunakan sebuah browser dengan menginputkan url website. Website sendiri memiliki beberapa unsur yang sangat vital yaitu domain atau bisa dibaratkan sebagai merk, Hosting berfungsi untuk penyimpanan database yang diperlukan untuk membuat suatu website dan terakhir konten yang merupakan isi dari website tersebut tanpa konten website akan terlihat kosong.

\subsection{Hamster}

Hamster merupakan salah satu hewan pengerat yang berdarah dingin, yang berati kondisi suhu disekitar harus dijaga agar mengurangi tingkat kesetresan hamster tersebut oleh karena itu suhu ruangannya harus dijaga dan suhu atau temperatur yang ideal bagi hamster adalah $18^{\circ}$ hingga $24^{\circ}$ Celsius. Selain suhu kelembaban ruangan meruapakan salah satu hal perlu diperhatikan juga. Untuk hamster kelembaban yang baik bagi hamster adalah $40 \%$ hingga $70 \%$. Salah satu usaha yang dapat dilakukan pemilik hamster adalah dengan memberikan alas berupa batu zeolite untuk menjaga suhu dan kelembaban kandang. (Pipa Elliot, MRCVS).

\subsection{Arduino Uno}

Caratekno (2015) Arduino Uno merupakan board mikrokontroler berbasis ATmega328 yang mempunyai 14 input digital yang kemudian terbagi menjadi 6 pin dapat digunakan untuk output $P W M, 6$ pin input analog, $16 \mathrm{MHz}$ osilator Kristal, koneksi USB, jack power, ICSP Header, serta tombol reset. Untuk mendukung supaya mikrokontroler bisa digunakan, cukup dengan cara menghubungkan board Arduino ke komputer menggunakan kabel USB atau menggunakan sumber tenaga yang lain seperti menggunakan adaptor AC-DC yang dihubungkan ke listrik ataupun menggunakan baterai sebagai sumber dayanya.

\subsection{NodeMCU}

Menurut Tedy Tri (2017) NodeMCU merupakan suatu platform IoT yang bersifat open source. NodeMCU sendiri merupakan perangkat keras yang dibekali System on chip ESP8266 dari ESP8266 buatan Espressif System, juga firmware yang digunakan menggunakan bahasa pemrograman lua. Istilah NodeMCU secara umum sebenarnya mengacu pada firmware yang digunakan dariada perangkat keras development kit.

\subsection{Sensor DHT11}

Menurut Ajie (2016) DHT11 merupakan salah satu modul sensor yang memiliki fungsi untuk mendeteksi nilai suhu dan nilai kelembaban udara yang mempunyai output tegangan analog sehingga dapat diolah lebih lanjut dengan menggunakan mikrokontroler. Sensor ini memiliki sebuah thermistor bertipe NTC (Negative Themprature Coefficient) membuat sensor ini tergolong kedalam elemen resistif.

\subsection{Sensor Ultrasonik}

Sensor Ultrasonik adalah suatu sensor yang berfungsi untuk medekteksi keberadaan suatu benda dengan memperkiraan jarak sensor dengan benda tersebut dengan menggunakan gelombang yang umum digunakan pada radar. (Bakhtiyar, 2019)

\subsection{Sensor Water Level}

Sensor water level merupakan sebuah alat yang digunakan untuk mengetahui nilai ketinggian air dengan output analog kemudian diolah oleh mikrokontroler. Sensor ini berkerja dengan cara membaca nilai resistansi yang dihasilkan oleh air yang mengenai garis lempengan pada sensor. (Ajie, 2019)

\subsection{Kipas Angin}

Kipas angin merupakan suatu alat yang berfungsi untuk menghasilkan angin. Pada umumnya kipas angin digunakan sebagai pendingin udara, penyegar udara, pengering serta dapat juga sebagai ventilasi udara. Pada umumnya kipas angin yang ada 
pada rumah - rumah memiliki fungsi untuk menjaga suhu udara sekitar ruangan agar tidak melebihi batas suhu yang ditetapkan. (Alfian, 2018)

\subsection{Heater}

Heater adalah sebuah alat yang dimana dapat mengubah obyek agar dapat mengeluarkan atau memancarkan panas atau membuat obyek mencapai suhu lebih tinggi dengan memanfaatkan energi listrik. (Brainly, 2015)

\subsection{Ionizer}

Ionizer udara adalah perangkat yang menggunakan tegangan tinggi untuk mengionisasi udara molekul. Pengion udara digunakan dalam pemurni udara untuk menghilangkan partikel udara. (Wikipedia, 2021)

\section{METODE PENELITIAN}

\subsection{Kebutuhan Non Fungsional}

Adapun batasan layanan yang dapat disajikan oleh sistem monitoring kandang hamster berbasis android ini, yaitu:

a. Adaptor $12 \mathrm{v}$ untuk mendukung daya Arduino uno

b. Sistem yang digunakan berbasis website

c. Data akan terupdate sercara berkala tiap 15 detik

\subsection{Kebutuhan Fungsional}

Adapun kebutuhan yang berisikan proses proses yang akan dilakukan oleh smart farming hamster berbasis iot ini, meliputi:

a. Sistem dapat terhubungan dengan website

b. Sistem dapat menunjukkan indikator suhu pada kandang hamster

c. Sistem dapat menunjukkan indikator kelembaban pada kandang hamster

d. Sistem dapat menunjukkan ketersediaan pakan hamster

e. Sistem dapat menunjukkan ketersediaan air minum hamster

\subsection{Blok Diagram Sistem}

Blok diagram merupakan diagram dari suatu sistem, di mana bagian Arduino Uno berfungsi untuk pusat pemrosesan. Adapun Sensor DHT11, Ultrasonik, Water Level yang berfungsi sebagai inputan. Output yang dihasilkan ke users berupa website yang berisikan data - data dari sensor yang telah diproses oleh Arduino uno.

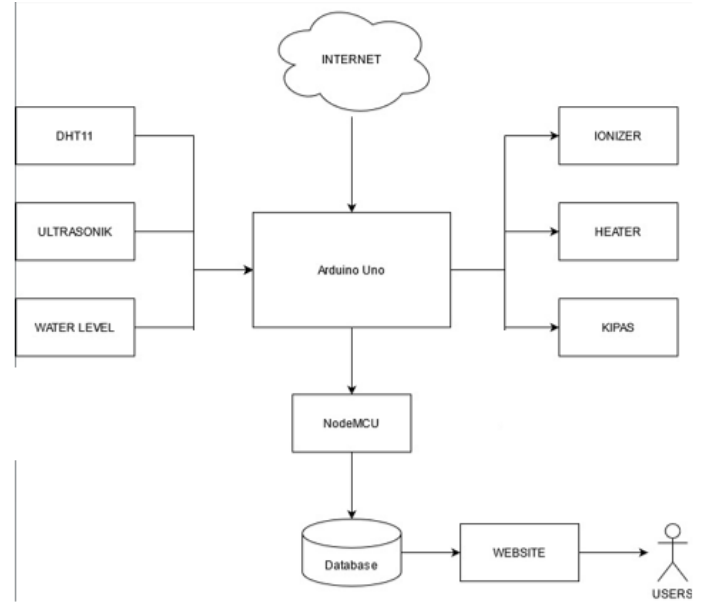

Gambar 1. Blok diagram sistem

\subsection{Flowchart Sistem}

Flowchart sistem ini bertujuan untuk menjelaskan proses alur berjalananya aplikasi seperti ditunjukkan pada Gambar 2.

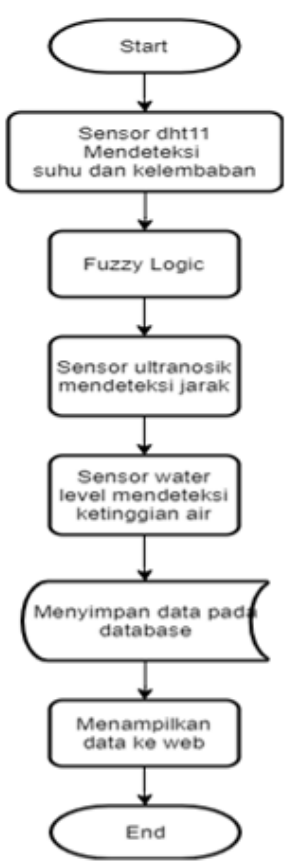

Gambar 2. Flowchart Sistem

Berdasarkan flowchart pada Gambar 2, Sistem diawali dengan sensor dht11 yang mana sensor tersebut mengambil data suhu dan kelembaban disekitar sensor kemudian masuk ke pemrosesan fuzzy logic yang mana nilai hasil fuzzy $\log c$ akan digunakan sebagai penentu output. Ada sensor ultrasonik yang memiliki fungsi untuk mengukur jarak sensor dengan pakan. Ada sensor water level yang dimana digunakan untuk mengukur ketinggian air dan ada sensor. Selanjutnya ada penampungan data yang telah didapat yang kemudian data tersebut akan ditampilkan pada website 


\section{HASIL DAN PEMBAHASAN}

\subsection{Pengujian Website}

Pengujian website dilakukan untuk mengetahui fungsional fitur - fitur pada website dapat berjalan dengan baik pada browser - browser yang tersedia. Pada penelitian ini browser yang digunakan adalah Chrome, Microsoft Edge dan Mozilla Firefox. Pengujian yang dilakukan adalah sebagai berikut:

Tabel 1. Hasil Pengujian Website

\begin{tabular}{|l|c|c|c|}
\hline \multirow{2}{*}{ Aspek } & $\begin{array}{c}\text { Chrome } \\
\text { Version } \\
91.0 .4472 .106\end{array}$ & $\begin{array}{c}\text { Miscosoft } \\
\text { Edge } \\
\text { Version } \\
91.0 .864 .54\end{array}$ & $\begin{array}{c}\text { Mozilla } \\
\text { Firefox } \\
\text { Version } \\
89\end{array}$ \\
\cline { 2 - 4 } $\begin{array}{l}\text { Menampilkan } \\
\text { Kondisi Suhu }\end{array}$ & $\sqrt{ }$ & $\sqrt{ }$ & $\sqrt{ }$ \\
\hline $\begin{array}{l}\text { Menampilkan } \\
\text { Kondisi } \\
\text { Kelembaban }\end{array}$ & $\sqrt{ }$ & $\sqrt{ }$ & $\sqrt{ }$ \\
\hline $\begin{array}{l}\text { Menampilkan } \\
\text { status Pakan }\end{array}$ & $\sqrt{ }$ & $\sqrt{ }$ & $\sqrt{ }$ \\
\hline $\begin{array}{l}\text { Menampilkan } \\
\text { status air minum }\end{array}$ & $\sqrt{ }$ & $\sqrt{ }$ \\
\hline $\begin{array}{l}\text { Menampilkan } \\
\text { status kandang }\end{array}$ & $\sqrt{ }$ & $\sqrt{ }$ & $\sqrt{ }$ \\
\hline $\begin{array}{l}\text { Menampilkan } \\
\text { status sensor } \\
\text { yang error }\end{array}$ & $\sqrt{ }$ & & \\
\hline
\end{tabular}

\subsection{Pengujian Hardware}

Pengujian komponen dari alat Sistem monitoring kandang hamster atau Smart Farming Hamster. Sistem monitoring kandang hamster atau Smart Farming Hamster terdiri dari Arduino uno, NodeMcu, sensor ultrasonik, sensor dht11, sensor water level, servo, heater, ionizer, serta kipas $d c 12 \mathrm{v}$. Implementasi komponen yang terhubung pada Arduino uno diletakkan pada sebua breadboard. Adapun implementasi hardware ditunjukkan pada Gambar

Smart Farming Hamster berarsis IOT ini menggunakan wadah yang terbuat dari plastik yang memiliki ukuran $24 \times 18 \times 18$ centimeter. Wadah plastik tersebut dibuatkan lubang dibagian atas dan samping untung membantu keluar masuknya udara untuk kandang hamster supaya hamster tetap mendapatkan sirkulasi udara.

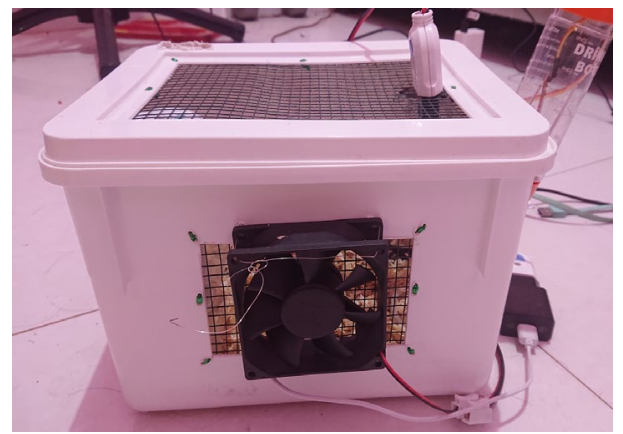

Gambar 3. Implementasi Smart Farming Hamster

\subsection{Pengujian Sensor DHT11}

Pengujian dht11 untuk mendapatkan nilai suhu yang dilakukan pada penelitian ini adalah sebagai berikut:

Tabel 3. Hasil Pengujian DHT11 Suhu

\begin{tabular}{|c|c|c|c|c|}
\hline \multirow{2}{*}{ Waktu } & \multicolumn{2}{|c|}{ Suhu } & \multirow{2}{*}{ Error } & \multirow{2}{*}{ Akurat } \\
\cline { 2 - 3 } & Sensor & Termometer & & \\
\hline $13: 14: 55$ & 31.0 & 30.1 & $2.99 \%$ & $97.01 \%$ \\
\hline $16: 07: 52$ & 32.0 & 28.8 & $3.85 \%$ & $96.15 \%$ \\
\hline $17: 33: 32$ & 29.0 & 28.1 & $3.20 \%$ & $96.80 \%$ \\
\hline $22: 40: 34$ & 29.0 & 28.0 & $3.57 \%$ & $96.43 \%$ \\
\hline $07: 02: 54$ & 27.0 & 27.6 & $2.17 \%$ & $97.83 \%$ \\
\hline
\end{tabular}

Berdasarkan hasil pengujian pada tabel 3 menunjukan bahwa setelah melakukan 5 kali percobaan sensor dht11 dapat membaca nilai suhu sekitar dengan tingkat rata - rata akurat $96.84 \%$ dan nilai maximum yang diapat $97.83 \%$ dan nilai minimum yang didapat $96.15 \%$.

Pengujian dht11 untuk mendapatkan nilai kelembaban yang dilakukan pada penelitian ini adalah sebagai berikut:

Tabel 4. Hasil Pengujian DHT11 Kelembaban

\begin{tabular}{|c|c|c|c|c|}
\hline \multirow{2}{*}{ Waktu } & \multicolumn{2}{|c|}{ Suhu } & \multirow{2}{*}{ Error } & \multirow{2}{*}{ Akurat } \\
\cline { 2 - 3 } & Sensor & Termometer & & \\
\hline $13: 17: 10$ & $54 \%$ & $77 \%$ & $29.87 \%$ & $70.13 \%$ \\
\hline $16: 11: 42$ & $56 \%$ & $81 \%$ & $30.86 \%$ & $69.14 \%$ \\
\hline $17: 35: 27$ & $53 \%$ & $68 \%$ & $22.05 \%$ & $77.95 \%$ \\
\hline $22: 42: 02$ & $62 \%$ & $72 \%$ & $13.8 \%$ & $86.2 \%$ \\
\hline $07: 05: 26$ & $73 \%$ & $84 \%$ & $13.09 \%$ & $86.91 \%$ \\
\hline
\end{tabular}

Berdasarkan hasil pengujian pada tabel 4 menunjukan bahwa setelah melakukan 5 kali percobaan sensor dht11 dapat membaca nilai kelembaban sekitar dengan tingkat rata - rata akurat $78.06 \%$. Nilai maximum akurat adalah $86.91 \%$ serta nilai akurat minimum yang didapatkan adalah $69.14 \%$

\subsection{Pengujian Sensor Ultrasonik}

Pengujian dht11 untuk mendapatkan nilai jarak sensor dengan pakan hamster yang dilakukan pada penelitian ini adalah sebagai berikut:

Tabel 5. Hasil Pengujian Sensor Ultrasonik

\begin{tabular}{|c|c|c|c|c|}
\hline \multirow{2}{*}{ Percobaan } & \multicolumn{2}{|c|}{ Ultrasonik } & \multirow{2}{*}{ Error } & \multirow{2}{*}{ Akurat } \\
\cline { 2 - 3 } & Sensor & Penggaris & & \\
\hline 1 & 6.55 & 6.9 & $5.07 \%$ & $94.93 \%$ \\
\hline 2 & 9.54 & 10.1 & $9.30 \%$ & $90.70 \%$ \\
\hline 3 & 8.84 & 9.7 & $8.86 \%$ & $91.14 \%$ \\
\hline 4 & 4.78 & 5.2 & $8.07 \%$ & $91.93 \%$ \\
\hline 5 & 5.37 & 5.8 & $7.41 \%$ & $92.59 \%$ \\
\hline
\end{tabular}

Berdasarkan hasil pengujian pada tabel 5 menunjukan bahwa setelah melakukan 5 kali percobaan sensor ultrasonik dapat membaca nilai jarak sensor dengan pakan hamster. Dengan percobaan ini didapatkan bahwa nilai maximum akurat $94.93 \%$ dan nilai minimum akurat yang diapat $90.70 \%$ 


\subsection{Pengujian Sensor Water Level}

Pengujian water level untuk mendapatkan nilai ketinggian air minum hamster yang dilakukan pada penelitian ini adalah sebagai berikut:

Tabel 6. Hasil Pengujian Sensor Ultrasonik

\begin{tabular}{|c|c|c|c|c|}
\hline \multirow{2}{*}{ Percobaan } & \multicolumn{2}{|c|}{ Sensor Water Level } & \multirow{2}{*}{ Error } & \multirow{2}{*}{ Akurat } \\
\cline { 2 - 3 } & Sensor & Penggaris & & \\
\hline 1 & 1.13 & 3.1 & $63.54 \%$ & $36.46 \%$ \\
\hline 2 & 0.80 & 1.4 & $42.85 \%$ & $57.15 \%$ \\
\hline 3 & 1.20 & 3.2 & $62.5 \%$ & $37.5 \%$ \\
\hline 4 & 1.46 & 4.4 & $66.81 \%$ & $33.19 \%$ \\
\hline 5 & 0.44 & 1.3 & $66.15 \%$ & $33.85 \%$ \\
\hline
\end{tabular}

Berdasarkan hasil pengujian pada tabel 6 menunjukan bahwa setelah melakukan 5 kali percobaan sensor water level dapat membaca nilai nilai dari ketinggian air minum. Dengan percobaan ini didapatkan bahwa rata - rata akurat $39.43 \%$ dan nilai maximum akurat yang didapat $57.15 \%$ serta nilai minimum akurat adalah $33.19 \%$

\subsection{Pengujian Metode Fuzzy}

Pengujian metode fuzzy tsukamoto untuk mendapatkan nilai penentu output yang dilakukan pada penelitian ini adalah sebagai berikut:

Tabel 7. Hasil Perbandingan Fuzzy

\begin{tabular}{|c|c|c|c|c|}
\hline & $\begin{array}{c}\text { Nilai } \\
\text { Manual }\end{array}$ & $\begin{array}{c}\text { Nilai } \\
\text { Arduino }\end{array}$ & Error & Akurant \\
\hline Ionizer & 35 & 35 & $0 \%$ & $100 \%$ \\
\hline Heater & 35 & 35 & $0 \%$ & $100 \%$ \\
\hline Kipas & 55 & 55 & $0 \%$ & $100 \%$ \\
\hline
\end{tabular}

Berdasarkan hasil pengujian pada tabel 7 menunjukan bahwa nilai dari perhitungan manual dengan nilai fuzzy dari arduino memiliki tingkat akurat $100 \%$ untuk ionizer, $100 \%$ untuk heater dan $100 \%$ untuk kipas.

\subsection{Pengujian Metode Fuzzy pada Ionizer}

Pengujian metode fuzzy tsukamoto untuk mendapatkan nilai penentu output ionizer yang dilakukan pada penelitian ini adalah sebagai berikut:

Tabel 8. Hasil Perbandingan Fuzzy

\begin{tabular}{|c|c|c|c|c|}
\hline $\begin{array}{c}\text { Suhu / } \\
\text { Kelembaban }\end{array}$ & $\begin{array}{c}\text { Nilai } \\
\text { Manual }\end{array}$ & $\begin{array}{c}\text { Nilai } \\
\text { Arduino }\end{array}$ & Error & Akurant \\
\hline $29^{\circ} \mathrm{C} / 67 \%$ & 35 & 35 & $0 \%$ & $100 \%$ \\
\hline $25^{\circ} \mathrm{C} / 55 \%$ & 30 & 30 & $0 \%$ & $100 \%$ \\
\hline $31^{\circ} \mathrm{C} / 50 \%$ & 30 & 30 & $0 \%$ & $100 \%$ \\
\hline $26^{\circ} \mathrm{C} / 80 \%$ & 35 & 35 & $0 \%$ & $100 \%$ \\
\hline $26^{\circ} \mathrm{C} / 77 \%$ & 50 & 50 & $0 \%$ & $100 \%$ \\
\hline
\end{tabular}

Berdasarkan hasil pengujian pada tabel 8 menunjukan bahwa nilai dari perhitungan manual dengan nilai perhitunggan fuzzy dari arduino untuk output ionizer memiliki tingkat akurat $100 \%$ untuk ionizer

\subsection{Pengujian Metode Fuzzy pada Heater}

Pengujian metode fuzzy tsukamoto untuk mendapatkan nilai penentu output heater yang dilakukan pada penelitian ini adalah sebagai berikut:

Tabel 9. Hasil Perbandingan Fuzzy

\begin{tabular}{|c|c|c|c|c|}
\hline $\begin{array}{l}\text { Suhu dan } \\
\text { Kelembaban }\end{array}$ & $\begin{array}{c}\text { Nilai } \\
\text { Manual }\end{array}$ & $\begin{array}{c}\text { Nilai } \\
\text { Arduino }\end{array}$ & Error & Akurant \\
\hline $29^{\circ} \mathrm{C} / 67 \%$ & 35 & 35 & $0 \%$ & $100 \%$ \\
\hline $25^{\circ} \mathrm{C} / 55 \%$ & 30 & 30 & $0 \%$ & $100 \%$ \\
\hline $31^{\circ} \mathrm{C} / 50 \%$ & 30 & 30 & $0 \%$ & $100 \%$ \\
\hline $26^{\circ} \mathrm{C} / 80 \%$ & 35 & 35 & $0 \%$ & $100 \%$ \\
\hline $26^{\circ} \mathrm{C} / 77 \%$ & 30 & 30 & $0 \%$ & $100 \%$ \\
\hline
\end{tabular}

Berdasarkan hasil pengujian pada tabel 9 menunjukan bahwa nilai dari perhitungan manual dengan nilai perhitunggan fuzzy dari arduino untuk output heater memiliki tingkat akurat $100 \%$ untuk heater

\subsection{Pengujian Metode Fuzzy pada Kipas}

Pengujian metode fuzzy tsukamoto untuk mendapatkan nilai penentu output Kipas yang dilakukan pada penelitian ini adalah sebagai berikut:

Tabel 10. Hasil Perbandingan Fuzzy

\begin{tabular}{|c|c|c|c|c|}
\hline $\begin{array}{c}\text { Suhu dan } \\
\text { Kelembaban }\end{array}$ & $\begin{array}{c}\text { Nilai } \\
\text { Manual }\end{array}$ & $\begin{array}{c}\text { Nilai } \\
\text { Arduino }\end{array}$ & Error & Akurant \\
\hline $29^{\circ} \mathrm{C} / 67 \%$ & 55 & 55 & $0 \%$ & $100 \%$ \\
\hline $25^{\circ} \mathrm{C} / 55 \%$ & 50 & 50 & $0 \%$ & $100 \%$ \\
\hline $31^{\circ} \mathrm{C} / 50 \%$ & 70 & 70 & $0 \%$ & $100 \%$ \\
\hline $26^{\circ} \mathrm{C} / 80 \%$ & 55 & 55 & $0 \%$ & $100 \%$ \\
\hline $26^{\circ} \mathrm{C} / 77 \%$ & 50 & 50 & $0 \%$ & $100 \%$ \\
\hline
\end{tabular}

Berdasarkan hasil pengujian pada tabel 10 menunjukan bahwa nilai dari perhitungan manual dengan nilai perhitunggan fuzzy dari arduino untuk output kipas memiliki tingkat akurat maksimal 100\%

\subsection{Pengujian Software Sistem}

Pengujian software sistem yang dilakukan pada penelitian ini adalah sebagai berikut:

Tabel 11. Hasil Perbandingan Fuzzy

\begin{tabular}{|c|l|c|c|c|}
\hline \multirow{2}{*}{ No } & \multicolumn{1}{|c|}{ Aspek } & $\begin{array}{c}\text { Chrome } \\
\text { Version } \\
91.0 .4472 .\end{array}$ & $\begin{array}{c}\text { Miscosoft } \\
\text { Edge } \\
\text { Version } \\
91.0 .864 .54\end{array}$ & $\begin{array}{c}\text { Mozilla } \\
\text { Firefox } \\
\text { Version } \\
89\end{array}$ \\
\hline 1 & $\begin{array}{l}\text { Menampilkan } \\
\text { Kondisi Suhu }\end{array}$ & $\sqrt{ }$ & $\sqrt{ }$ & $\sqrt{ }$ \\
\hline 2 & $\begin{array}{l}\text { Menampilkan } \\
\text { Kondisi } \\
\text { Kelembaban }\end{array}$ & $\sqrt{ }$ & $\sqrt{ }$ & $\sqrt{ }$ \\
\hline 3 & $\begin{array}{l}\text { Menampilkan } \\
\text { status Pakan }\end{array}$ & $\sqrt{ }$ & $\sqrt{ }$ & $\sqrt{ }$ \\
\hline 4 & $\begin{array}{l}\text { Menampilkan } \\
\text { status air } \\
\text { minum }\end{array}$ & $\sqrt{ }$ & $\sqrt{ }$ & $\sqrt{ }$ \\
\hline 5 & $\begin{array}{l}\text { Menampilkan } \\
\text { status kandang }\end{array}$ & $\sqrt{ }$ & $\sqrt{ }$ & $\sqrt{ }$ \\
\hline 6 & $\begin{array}{l}\text { Menampilkan } \\
\text { status sensor } \\
\text { yang error }\end{array}$ & $\sqrt{ }$ & \\
\hline
\end{tabular}


Berdasarkan hasil pengujian pada tabel 11 menunjukan bahwa software sistem dapat berkerja dengan baik pada beberapa browser sebagai berikut yaitu Chrome versi 91.0.4.472, Microsoft Edge versi 91.0.864.54 dan Mozilla Firefox versi 89.s.

\section{KESIMPULAN DAN SARAN}

\subsection{Kesimpulan}

Berdasarkan beberapa pengujian yang telah dilakukan didapatkan kesimpulan :

1. Berdasarkan hasil pengujian browser bahwa aplikasi yang dibuat dapat berjalan dengan baik pada web browser Chrome versi 91.9.4472.106, Microsoft Edge versi 91.0864.54 dan Mozilla Firefox versi 89.

2. Berdasarkan hasil pengujian sensor $d h t 11$ yang telah dilakukan bahwa sensor dht11 memiliki tingkat akurat rata - rata 96.84\% dengan nilai akurat tertinggi $97.83 \%$ dan terendah $96.15 \%$ untuk deteksi suhu dan nilai akurat rata - rata $78.06 \%$ dengan nilai akurat tertinggi $86.91 \%$ dan akurat terendah $69.14 \%$ untuk deteksi kelembaban.

3. Berdasarkan hasil pengujian sensor ultrasonik yang telah dilakukan didapatkan data nilai akurasi paling tinggi adalah $94.93 \%$ dan nilai akurasi terendah adalah $90.70 \%$

4. Berdasarkan hasil pengujian sensor water level yang telah dilakukan didapatkan data nilai akurasi rata - rata $39.43 \%$ dengan nilai akurasi paling tinggi adalah $57.15 \%$ dan nilai akurasi terendah adalah $33.19 \%$

\subsection{Saran}

Berdasarkan penelitian yang telah dilakukan, maka penulis dapat memberikan saran-saran untuk pengembangan selanjutnya antar lain :

1. Menambahkan buzzer sebagai peringatan apabila terdapat sensor yang error.

2. Menambahkan fitur keamanan kandang dengan menyediakan tempat khusus yang dipasangi sensor ultrasonik dan buzer yang berfungsi apabila kandang dipindahkan dan sensor ultrasonik yang digunakan untuk mendeteksi jarak. Jika jarak yang didapatkan lebih jauh dari yang ditentukan maka buzzer berfungsi untuk membunyikan alarm.

\section{DAFTAR PUSTAKA}

[1] Shaifany. 2019. MOBILE IOT (INTERNET OF THINGS) UNTUK PEMANTAUAN KUALITAS AIR HABITAT IKAN HIAS PADA AKUARIUM MENGGUNAKAN LOGIKA FUZZY. Malang: JATI (Jurnal Mahasiswa Teknik Informatika)

[2] Pratama, Muhammad Rizki, 2016, Implementasi Fuzzy Logic dalam Perancangan Drum Elektrik Berbasis Midi Menggunakan Perangkat Android dan Arduino Uno, Jurnal Ilmu Komputer

[3] Abel. 2017. PENERAPAN ALGORITMA FUZZY LOGIC SUGENO PADA SISTEM PEMBERI MAKAN LOBSTER OTOMATIS DAN MONITORING KEKERUHAN AIR. Malang: JATI (Jurnal Mahasiswa Teknik Informatika)

[4] Lararenjana, Edelweis. 2020. "6 Tips Merawat Hamster bagi Pemula, Wajib diketahui", https://www.merdeka.com/jatim/6-tipsmerawat-hamster-bagi-pemula-wajib-diketahuikln.html, diakses pada 25 Maret 2021

[5] Arsada, Bakhtiyar. "Aplikasi Sensor Ultrasonik Untuk Deteksi Posisi Jarak Pada Ruang Menggunakan Arduino Uno". Jurnal Teknik Elektro. Volume 06 Nomor 02 Tahun 2017, 137 -145 .

[6] Caratekno.com. (6 Juli 2015). Pengertian Arduino UNO Mikrokontroler ATMega328. Diakses pada 25 Maret 2021, dari https://www.caratekno.com/pengertian-arduinouno-mikrokontroler/ 